\title{
The Fate of Chlorpyrifos on Tobacco during Smoking *
}

\author{
by N.M. Chopra and T. H. Zuniga
}

Tobacco and Pesticide Research Laboratory, North Carolina Agricultural and Technical State University, Greensboro, North Carolina, U.S.A.

\section{SUMMARY}

Cigarettes made from flue-cured tobacco, treated with different amounts of chlorpyrifos, were smoked according to Federal Trade Commission specifications, and the chlorpyrifos levels in the butts, various ashes, and mainstream and sidestream smokes were determined. Of all the chlorpyrifos in a cigarette, $28 \%$ to $29.5 \%$ was left in the butts, $13.5 \%$ to $15 \%$ and $2.0 \%$ to 4.6\% were transferred into mainstream and sidestream smokes, respectively, and about $52 \%$ to $55 \%$ was either combusted or decomposed into unknown fragments. The various ashes did not show any detectable amount of chlorpyrifos.

\section{ZUSAMMENFASSUNG}

Zigaretten aus „flue-cured ${ }^{\alpha}$-Virgintabak, die mit Chlorpyrifos in unterschiedlicher Dosierung behandelt worden waren, wurden nach den Richtlinien der Aufsichtsbehörde der Vereinigten Staaten von Amerika (Federal Trade Commission) verraucht. Die Untersuchung des Chlorpyrifosgehaltes in Stummel und Asche sowie im

\footnotetext{
* Received: 9h July 1986 - zccepted: 8th February 1989.
}

Rauch von Haupt- und Nebenstrom zeigte, daß die im Zigarettentabak enthaltene Gesamtmenge Chlorpyrifos zu $28 \%$ bis $29,5 \%$ im Stummel zurückbleibt, zu $13,5 \%$ bis $15 \%$ in den Hauptstromrauch und zu $2,0 \%$ bis $4,6 \%$ in den Nebenstromrauch übergeht und zu ungefähr $52 \%$ bis $55 \%$ entweder verbrennt oder zu unbekannten Bruchstücken pyrolysiert wird. In der Asche ließ sich Chlorpyrifos nicht nachweisen.

\section{RESUME}

Des cigarettes confectionnées avec du tabac efluecured " (Virginie) traité par des quantités variables de chlorpyrifos ont été fumées selon les normes définies par les autorités américaines (Federal Trade Commission). L'examen des teneurs en chlorpyrifos des cendres, des mégots, de la fumée du courant principal et de la fumée du courant secondaire a montré que la quantité totale de chlorpyrifos contenue initialement dans la cigarette se répartissait comme suit: $28 \%$ à $29,5 \%$ restent dans le mégot, $13,5 \%$ à $15 \%$ passent dans la fumée principale et de $2,0 \%$ à $4,6 \%$ dans la fumée secondaire; environ $52 \%$ à $55 \%$ du chlorpyrifos sont détruits par la combustion ou pyrolysés en fractions inconnues. Aucune trace de chlorpyrifos n'est décelable dans les cendres. 


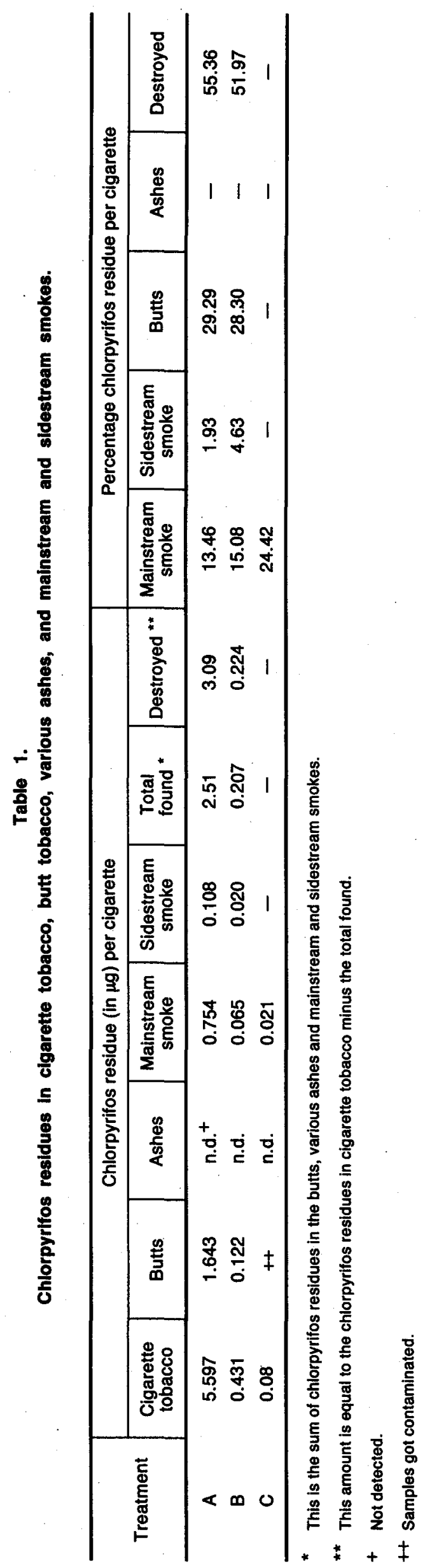


INTRODUCTION

There are three sets of data which are essential for the determination of the suitability of a pesticide for use on tobacco. They are: [1] the amount of pesticide residue in cured tobacco, [2] pesticide-transfer rate into mainstream smoke, and [3] pesticide-transfer rate into sidestream smoke. The first information is required to meet the pesticide tolerances imposed by different tobaccogrowing and tobacco-importing and exporting countries. Extensive work has been done on this aspect. In the U.S.A. these determinations are routinely carried out at the Pesticide Residue Research Laboratory, North Carolina State University, Raleigh, N.C. The second set of data is required for assessing the hazard the pesticide use may pose to the smoker. Several, though not enough, publications have appeared which give such information (see Cropra et al. (1) and references cited therein). The third set of data is required for assessing the hazard the pesticide use may pose to the non-smoker exposed to the environmental cigarette smoke generated. Unfortunately, to the best of our knowledge, there is only one publication (1) on this topic. Further information on this aspect is of great importance.

Chlorpyrifos $\quad[0,0$-diethyl $0-3,5,6$-trichloro-2-pyridyl phosphorothioate] is one of the soil insecticides used on tobacco for the control of cutworms. Though studies on the chlorpyrifos residues in tobacco have been reported (3), nothing to our knowledge has been published on the chlorpyrifos residues in tobacco mainstream and sidestream smokes. In this paper we have attempted to meet that need.

\section{EXPERIMENTAL}

\section{Materials}

Acetonitrile, Pesticide Grade (Fisher Scientific Co.), was used without further purification. All other solvents, American Chemical Society (ACS) Grade, were distilled before use.

Chlorpyrifos (purity: $99.8 \%$ ) was obtained from Dow Chemical Co., Midland, Michigan, U.S.A. Qualitatively and quantitatively, the chlorpyrifos sample gave only one peak in the GLC using electron-capture and flameionization detector. Thus, any error which may ensue from taking the purity of chlorpyrifos at its face value should be well within the experimental error.

Tobacco: tobacco, variety McNair 944, was grown in the upper coastal plains of North Carolina, U.S.A. During its growth it was treated with the following chemicals per acre: Nemacur-Dasanit $2+4$ SC (preplant), 1 gal (U.S.); Tillon-Dyfonate (preplant), 1 gal (U.S.); Ridomil, 1 qt (U.S.); Enide 50 W, $10 \mathrm{lb}$; Lannate, 1 qt (U.S.); Off-Shoot T, $2 \mathrm{gal}$ (U.S.); Orthene, $1 \mathrm{lb}$; and Royal MH-
$30,1.5 \mathrm{gal}$ (U.S.). The tobacco leaves were harvested and flue-cured in the usual way. The cured tobacco leaves were stemmed by hand and the laminae shredded (cut width: $0.85 \mathrm{~mm}$ ). The shredded tobacco was divided into four portions. Of these, three portions were sprayed with different amounts of chlorpyrifos/acetone solutions by The American Tobacco Company, Hopewell, $\mathrm{Va}$, the fourth being the untreated standard. The chlorpyrifos-treated and untreated samples were then manufactured into $85 \mathrm{~mm}$ long unfiltered cigarettes in a manner similar to commercial cigarettes.

\section{Smoking of Cigarettes}

The cigarettes were humidified in a humidifying chamber to a moisture content of $12 \%$ on dry-weight basis before smoking. The smoking was done according to Chopra et al. (1) and to the Federal Trade Commission (FTC) specifications (2), i.e. puff duration, 2 seconds; puff frequency, 1 puff / min; puff volume, $35 \mathrm{ml}$; butt length, $23 \mathrm{~mm}$. For each determination one hundred cigarettes were smoked on a smoking machine, with 5 cigarettes being smoked at a time. The mainstream and sidestream smokes were passed through separate trains consisting of one Cambridge filter pad followed by four traps containing about $50 \mathrm{ml}$ of pentane, cooled to $-80^{\circ} \mathrm{C}$. After each 5 cigarettes were smoked, the old Cambridge filter pad was replaced by a new Cambridge filter pad. When all 100 cigarettes had been smoked, all the Cambridge filter pads were collected and extracted with pentane. The pentane extracts were combined with the respective cold-trap solutions to give mainstream and sidestream-smoke condensates. At the same time, the butts and various ashes were collected and weighed. The average weight of a cigarette butt was $0.31 \mathrm{~g}$, and the ash weight was 0.095 per cigarette.

The cigarettes employed in this study differed from the commercial American cigarettes in the following respects:

(a) The tobacco used in commercial American cigarettes is a blend of flue-cured, Burley, Turkish, and Maryland tobaccos. Further, the commercial cigarettes contain flavors and additives, etc. The cigarettes used in this study were made of tobacco from a single cultivar and did not contain any flavor or additive.

(b) The commercial cigarette tobacco contains tobacco to which technical-grade pesticides are applied while the plant is still growing. As to the tobacco used in this study, chlorpyrifos (purity: $\mathbf{9 9 . 8 \% )}$ ) was applied to the shredded cured tobacco.

Further, the cigarettes used in this study were smoked according to the Federal Trade Commission specifications, as described above. 
Determination of Chlorpyrifos Residues in Cigarette Tobacco, Cigarette Mainstream and Sidestream Smokes, Butts and various Ashes, and the Determination of the Chlorpyrifos-Transfer Rates from Cigarette Tobacco into Cigarette Mainstream and Sidestream Smokes

\section{Determination $A$}

Determination of Chlorpyrifos in Cigarette Tobacoo: Tobacco, from a representative sample of check (untreated) cigarette tobacco (moisture content: $12 \%$ ), was ground into fine powder in a blender. The powdered tobacco was then divided into seven 5 gram lots and the aliquots fortified with $0.0,1.0,2.0,4.0,6.0,8.0$ and $10.0 \mathrm{ppm}$ of chlorpyrifos. Each sample was then shaken on a wrist-action shaker for $16 \mathrm{~h}$ with $100 \mathrm{ml}$ of acetonitrile, filtered under partial vacuum, and the residue washed with two $15 \mathrm{ml}$ lots of acetonitrile. $75 \mathrm{ml}$ of $2 \%$ sodium-chloride solution was then added to the filtrate and the mixture extracted twice with $50 \mathrm{ml}$ of pentane. The two pentane extracts were combined, treated with anhydrous sodium sulfate, filtered, diluted to a known volume with pentane, and analyzed by GLC. The recoveries ranged from $100.1 \%$ at the lower chlorpyrifos concentrations to $89 \%$ at the higher chlorpyrifos concentrations.

\section{Determination $B$}

Determination of Chlorpyrifos in various Cigarette Ashes: Five 1.0 gram ash samples from cigarettes made from untreated tobacco were fortified with $0.0,1.0,2.0,4.0$ and $6.0 \mathrm{ppm}$ of chlorpyrifos. To each sample acetonitrile $(25 \mathrm{ml})$ was added and the mixture shaken overnight on a wrist-action shaker. The mixture was filtered under partial vacuum, and the residue washed with $2 \mathrm{ml}$ of acetonitrile. The filtrate and the washings were combined and $20 \mathrm{ml}$ of $2 \%$ sodium-chloride solution added to the mixture. The resulting mixture was twice extracted with $12.5 \mathrm{ml}$ of pentane. The pentane extract was then treated with anhydrous sodium sulfate, filtered, diluted to a volume of $25 \mathrm{ml}$ and analyzed by GLC. The recoveries ranged from $85 \%$ to $98 \%$.

\section{Determination C}

Determination of Chlorpyrifos in Cigarette Mainstream and Sidestream Smokes: Five batches of 100 cigarettes made from untreated tobacco were smoked as described above and their mainstream-smoke condensates were combined. The combined condensate was divided into five equal parts and the aliquots fortified with 0.0 , $0.5,1.0,2.0$, and $5.0 \mathrm{ppm}$ of chlorpyrifos. Each aliquot was then diluted to $150 \mathrm{ml}$ with pentane. The pentane solution was extracted with $50 \mathrm{ml}$ of acetonitrile and then extracted with $75 \mathrm{ml}$ of $2 \%$ sodium-chloride solution. The pentane layers were treated with anhydrous sodium sulfate, filtered, and concentrated to a volume of $100 \mathrm{ml}$, and then analyzed by GLC.

The procedures employed for the determinations A, B and $C$ were also used for determining chlorpyrifos residues in: cigarette and cigarette-butt tobacco (Determination A), cigar ashes (Determination B), and mainstream and sidestream smokes (Determination $C$ ).

Since the GLC profiles of the cigarette and cigarettebutt tobacco were very similar to those of the samples used in Determination A, no separate chlorpyrifos-recovery curves were made with cigarette and cigarettebutt tobacco. Similarly, since the GLC profiles of mainstream and sidestream smokes were very similar, no separate recovery curves were made for them either. Again, no separate GLC recovery curves were made for the various cigarette ashes for the same reasons.

\section{GLC Parameters}

GLC unit:

Hewlett-Packard model 5880A GLC unit including Level IV integrator,

Column:

A $6 \mathrm{ft} \times 0.25$ in inside-diameter glass column packed with $3 \%$ OV-17 on GasChrom Q (MV),

Detector:

ECD,

Detector temperature:

$270^{\circ} \mathrm{C}$,

Injection-port temperature:

Oven temperatures:

Carrier gas:

$240^{\circ} \mathrm{C}$,

Initial, $190^{\circ} \mathrm{C}$; program rate, $10^{*} / \mathrm{min}$; final, $220^{\circ} \mathrm{C}$ (for $5 \mathrm{~min}$ ),

Carrier-gas

flow rate:

nitrogen,

Injection volume: $3 \mu \mathrm{l}$,

Chart speed: $\quad 1 \mathrm{~cm} / \mathrm{min}$.

The results of this study are shown in Table 1. Of all the chlorpyrifos present in the cigarette tobacco, $13.5 \%$ to $15 \%$ and $2.0 \%$ to $4.6 \%$ are transferred into the mainstream smoke and sidestream smoke, respectively, $28 \%$ to $29.5 \%$ is left in the butt*, an almost zero amount is in the various ashes, and $52 \%$ to $55 \%$ is either combusted or decomposed into unknown fragments.

\footnotetext{
* The amount of chlorpyrifos left behind in the cigarette butt is equal to the amount of chlorpyrifos originally present in the butt plus chlorpyrifos trapped by the butt from the chlorpyrifos present in the mainstream smoke minus ehlorpyrifos lost to the mainstream smoke due to the GLC action of the mainstream smoke.
} 
Of the three treatments reported, the values for treatment $C$ could not be determined with any great accuracy, and are probably a little too high.

\section{REFERENCES}

1. Chopra, N. M., M. M. Verma and T. H. Zuniga: On the fate of maleic hydrazide in tobacco smokes; $\mathrm{J}$. Agric Food Chem. 30 (1982) 672-676.

2. Pillsbury, H. C., C. C. Bright, K. J. O'Connor and F. W. Irish: Tar and nicotine in cigarette smoke; J. Assoc. Off. Anal. Chem. 52, No. 3 (1969) 458-462.

3. Toet, M. J., and L. Toet: Determination of chlorpyrifos (diethyl-3,5,6-trichloropyridyl phosphorothioate) in cured tobacco; Beitr. Tabakforsch. 8 (1976) 334338.
Acknowledgements

The authors wish to thank the School of Agriculture and Life Sciences, North Carolina State University, Raleigh, North Carolina; The American Tobacco Company, Hopewell, Virginia, for manufacturing the cigarettes; and Dow Chemical Co., Midland, Michigan, for donating chlorpyrifos.

These studies were supported by the U.S. Department of Agriculture with the $S E A / C R$ research grant No. NC $X-039-5-80-223-2$.

Autbors' address:

Tobacco and Pesticide Research Laboratory, North Carolina Agricultural and Technical State University,

Greensboro, N.C., 27411, U.S.A. 